\title{
The morphology of articular cartilage assessed by magnetic resonance imaging (MRI)
}

\section{Reproducibility and anatomical correlation}

\author{
F Eckstein ${ }^{1,2}$, H Sittek $^{1}, \mathrm{~S} \mathrm{Milz}^{2}$, R Putz $^{2}$ and M Reiser ${ }^{1}$ \\ ${ }^{1}$ Institut für Radiologische Diagnostik, Klinikum Großhadern, Marchioninistr. 15, D-81377 München, Germany \\ 2 Anatomische Anstalt, Ludwig-Maximilians Universität, Pettenkoferstr. 11, D-80336 München, Germany
}

Summary. Quantitative assessment of cartilage volume and thickness in a formalin-alcohol fixed specimen of a human patella was conducted with magnetic resonance imaging (MRI), as it is still unclear whether the morphology of normal and damaged cartilage can be accurately demonstrated with this technique. MR imaging was carried out at 1.0 $\mathrm{T}$ (section thickness $2 \mathrm{~mm}$, in-planeresolution $0.39-0.58 \mathrm{~mm}$ ) with the following pulse sequences: 1) T1weighted spin-echo, 2) 3D-MPRAGE, 3) 3D-FISP, 4) 3D-MTC-FISP, 5) 3D-DESS, 6) 3D-FLASH. Following imaging, the patella was sectioned perpendicular to the articular surface at intervals of $2 \mathrm{~mm}$ with a diamond band-saw. The volume of its cartilage was determined from the anatomical sections and the MR images, using a Vidas IPS 10 image analysing system (Kontron). Measu-

Correspondence to : F Eckstein, Anatomische Anstalt, Pettenkoferstr. 11, D-80336 München, Germany rements were carried out with and without the low-signal layer in the transitional zone between the articular cartilage and the subchondral bone. If the low-signal layer was included, the volume was overestimated with MRI by 16 to $19 \%$. Without the low-signal layer the volumes were less than those determined from the anatomical sections: T1-SE $-18,2 \%$, MPRAGE $-22.6 \%$, FISP $-17.1 \%$, MTC-FISP $-9.5 \%$, DESS $-9,3 \%$ and FLASH $-6.1 \%$. The coefficient of variation for a $6-$ fold determination of the volume amounted to between $6.2 \%$ (T1-SE) and $2.6 \%$ (FLASH). The FLASH sequence allowed the most valid and reproducible assessment of the cartilage morphology. The remaining difference from the real volume of the cartilage may be due to the fact that the calcified zone of the cartilage is not delineated by MRI.

Appréciation de la morphologie du cartilage articulaire par la résonance magnétique nucléaire (IRM). Reproductibilité et corrélations anatomiques
Résumé. L'évaluation quantitative de l'épaisseur et du volume du cartilage de patellas humaines, fixées dans un mélange d'alcool et de formol, a été réalisée en imagerie par résonance magnétique (IRM) car on ne sait encore avec exactitude si l'aspect morphologique du cartilage normal ou lésé peut être parfaitement démontré par cette technique. L'IRM a été réalisée sur un appareil $1.0 \mathrm{~T}$ (épaisseur de coupe : $2 \mathrm{~mm}$, résolution : 0,39-0,58 $\mathrm{mm}$ ) avec les séquences suivantes : 1) séquence en spin écho pondéré $T 1,2) 3 \mathrm{D}$ MRAGE, 3) 3D-FISP, 4) 3D-MTCFISP, 5) 3D-DESS, 6) 3D-FLASH. Après la réalisation de l'IRM, la patella était sectionnée tous les 2 $\mathrm{mm}$, perpendiculairement à sa surface articulaire, à l'aide d'une scie à ruban. Le volume de son cartilage était déterminé sur les coupes anatomiques et les images IRM grâce à un système d'analyse d'images Vidas IPS 10 (Kontron). Les mesures étaient réalisées avec et sans la couche en hyposignal correspondant à la zone transitionnelle située entre le cartilage articulaire et 
1'os sous-chondral. Lorsque cette couche en hyposignal était prise en compte, le volume était surestimé par l'IRM de 16 à 19\%. Lorsque cette couche en hyposignal n'était pas prise en compte, les volumes étaient inférieurs à ceux déterminés par les coupes anatomiques:

T1-SE : $-18,2 \%$, MPRAGE : $-22,6 \%$, FISP : - 17,1\%, MTC-FISP : - 9,5\%, DESS : $-9,3 \%$ et FLASH : $-6,1 \%$. La séquence FLASH permettait l'appréciation la plus correcte et la plus reproductible de la morphologie du cartilage. La différence persistante par rapport au volume réel du cartilage peut être due au fait que la zone calcifiée du cartilage n'est pas délimitée par l'IRM.

Key words: Articular cartilage Magnetic resonance imaging Cartilage thickness - Patella Knee joint

The integrity of the articular cartilage is a crucial prerequisite for the proper functioning of joints and the biological efficiency of the locomotor system. In most joint disorders the articular cartilage plays a central role in the pathogenetic process. Damage to its surface and/or internal structure will, with the passage of time, inevitably result in an impairment of the patient' $s$ physical activity and well-being. Therefore non-invasive and reliable imaging methods are needed for an accurate and reproducuble evaluation of the articular cartilage.

Magnetic resonance imaging (MRI) offers excellent soft-tissue contrast and a multiplanar representation of the intraarticular structures. T1- and T2-weighted spin-echo sequences have been widely used for imaging normal and damaged cartilage $[5,6,10-12,14-16,25,41$, 47]; so have gradient-echo sequences, such as FISP (fast imagining at steady state precision) or GRASS (gradient recalled acquisition at steady state) $[2,11-13,34,38,46]$ and FLASH (fast low angle shot) [2, $19,20,27,32]$.

However, only a very limited amount of scientific work has been directed towards a quantitative description of the morphology of articular cartilage in MR images. Some investigators have claimed that T1weighting is superior for the determination of cartilage thickness [6; 12], whereas $T 2$-weighting has been advocated for precise delineation of the articular surface $[10,39]$. Wrazidlo et al. [45], Chandani et al. [6] and Hodler et al. [15] have compared the cartilage thickness apparent in MR images with that in anatomical sections and Johnson et al. [16] with that in AP radiographs. However, in these investigations the definition and determination of corresponding measuring points appear to have posed major difficulties and the validity of the measurements was highly unsatisfactory. Tilting, rotation and translational displacement preclude precise correspondence of points that are meant to serve for comparison. Furthermore, it must be kept in mind that MR images represent volumes whereas anatomical sawcuts present surface sections. Thus, comparison of MR images and anatomical sections requires these factors to be taken into account.

The clear distinction between articular cartilage and synovial fluid poses considerable difficulties in MR images. Intraarticular contrast agents, which greatly enhance the delineation of the articular surface $[6,10,21,22]$, are invasive and cause patient discomfort. Therefore other techniques have been developed to improve contrast, such as MTC (magnetic transfer contrast) [39, 42-44], MPRAGE (magnetization-prepared rapid gradient echo) [29], DESS (dual echo at steady state) [24] and fat suppression [30, 37].

With regard to the internal structure of the cartilage, it is still unclear whether layers of different signal intensity represent specific microscopic zones $[12,14,18,23,25,30$, $33]$. Some authors have suggested that the low-signal layer in the transitional zone between cartilage and subchondral bone belongs, at least in part, to the articular cartilage [14, $25,40]$, whereas others strictly assign it to "cortical" bone $[18,31,35]$.

In view of these open questions, the objective of the present investigation was to precisely evaluate the validity and reproducibility of available MR sequences for determining articular cartilage thickness. To exclude uncertainties in finding corresponding measuring points, the total volume of the cartilage was assessed, once with and once without the low-signal layer in the transitional zone between cartilage and bone. The average cartilage thickness was then calculated by dividing the volume by the size of the articular surface. These results were checked for their reproducibility and compared with the values obtained from anatomical sections.

\section{Material and methods}

A human knee-joint, fixed in formalin-alcohol solution, was harvested from a woman whose age at the time of death was 84 years. Twenty milliliters of fluid consisting of 13.5 $\mathrm{ml}$ physiological saline and $6.5 \mathrm{ml}$ of $5 \%$ human albumin were injected into the joint space. This resulted in a total protein content of $1.7 \mathrm{~g} / \mathrm{l}$, which is equal to that of normal synovial fluid [36].

MRI was carried out, using a $1.0 \mathrm{~T}$ supraconductive magnet (Impact, Siemens, Erlangen, Germany) at a gradient field strength of $15 \mathrm{mT} / \mathrm{m}$ with a circular transmit and receive 
Table 1. Technical parameters of the pulse sequences employed Paramètres techniques des séquences utilisées

\begin{tabular}{lccccc}
\hline & FOV & reso & TR / TE & FA (TI) & No Aq \\
\hline T1-SE & 100 & $0,39 / 2$ & $570 / 15$ & $90^{\circ}$ & 6 \\
3-D MPRAGE & 150 & $0,58 / 2$ & $18 / 7$ & $8^{\circ}(1000)$ & 1 \\
3-D FISP & 150 & $0,58 / 2$ & $20 / 9$ & $75^{\circ}$ & 12 \\
3-D MTC-FISP & 100 & $0,39 / 2$ & $40 / 10$ & $25^{\circ}$ & 3 \\
3-D DESS & 110 & $0,43 / 2$ & $28 / 9$ & $40^{\circ}$ & 4 \\
3-D FLASH & 100 & $0,39 / 2$ & $31 / 11$ & $10^{\circ}$ & 4 \\
\hline
\end{tabular}

$F O V=$ field of view in $\mathrm{mm} ;$ reso $=$ resolution-voxel size $\mathrm{im} \mathrm{mm} ; T R=$ repetition time in $\mathrm{ms}$; $T E=$ echo time in $\mathrm{ms} ; T I=$ inversion time in $\mathrm{ms} ; F A=$ flip angle; $N o . A q=$ number of acquisitions

$F O V$ : champs de vue en mm; réso $=$ résolution - taille du voxel en $m m ; T R=$ temps de répétition en $\mathrm{ms} ; T E=$ temps d'écho en $\mathrm{ms} ; T \gamma=$ temps d'inversion en ms $F A=$ angle de bascule ; NoA $q=$ nombre d'acquisitions

knee coil. In order to ensure the imaging planes perpendicular to the patellar joint surface, a transverse scout view with a section thickness of $5 \mathrm{~mm}$ was obtained, followed by an image through the principal patellar ridge and a frontal image parallel to the subchondral plate. Another transverse scout view was then taken through the widest part of the patella (parallel to its base) and, finally, a sagittal slice running through the whole length of the principal ridge. MRI was then based on contiguous transverse images perpendicular to the joint surface of this last sagittal scout view.

T1-weighted spin-echo (T1-SE), 3-D MPRAGE, 3-D FISP, 3-D FISP with an implemented MTC prepulse (MTC-FISP), 3-D DESS and 3-D FLASH sequences were employed. For these pulse sequences a slice / partition thickness of $2 \mathrm{~mm}$ and a field of view (FOV) between 100 and $150 \mathrm{~mm}$ was taken, resulting in an in-plane-resolution of 0.39 to $0.58 \mathrm{~mm}$. The number of acquisitions was chosen so as to restrict total imaging time for each sequence to $15 \mathrm{~min}$. The repetition time (TR), echo time (TE) and flip angle (FA) were selected in accordance with current literature (Table 1).

Imaging was conducted with each of the sequences in turn. Then the knee-joint was repositioned and the procedure repeated to obtain a total of 6 sets of contiguous images with each pulse sequence. After MRI, the joint was opened and the patella removed. A diamond bandsaw (EXAKT) with a driving power of $200 \mathrm{~g}$ was used to obtain transverse sections perpendicular to the articular surface. The specimen was cut at intervals of $2 \mathrm{~mm}$ (accuracy $\pm 20 \mu \mathrm{m}$ ), the sawcut occupying $0.9 \mathrm{~mm}$. The actual section thickness was therefore $1,1 \mathrm{~mm}$, and the distance between the two sides of adjacent sections $0.9 \mathrm{~mm}$.

The morphometric analysis was carried out with a Vidas image analysing system (IPS $10 /$ Kontron). The anatomical sections and the MR images were digitized and the relevant areas and lengths measured interactively, using a digitizing table. The extension of the cartilage in each anatomical section (proximal and distal surfaces) was determined 6 times (Fig. 1a, b) and the reproducibility of this type of procedure assessed from a 50-fold measurement of one section. The mean values (given in square millimeters) were then multiplied by the width of the section interval $(2 \mathrm{~mm})$ and the total cartilage volume obtained by adding the partial volumes calculated from all sections. The size of the articular surface was derived from a threefold measurement of its length (in $\mathrm{mm}$ ) in each section (Fig. 1a, c) and multiplication with the width of the section interval. The average thickness of the patellar cartilage was finally calculated by dividing the total volume of the cartilage by the area of its articular surface. The means of the values derived from the proximal and distal sides of the sections were eventually used as a reference for comparison with the MR images.

In the MR images, the articular cartilage volume was determined once with (vol + , Fig. 2a) and once without (vol -, Fig. 2b) the lowsignal layer in the transitional zone between cartilage and subchondral bone. The size of the articular surface (surf) was determined as described for the anatomical sections (Fig. 2c), and two values for the mean patellar cartilage thickness calculated (thick + and thick -) by dividing vol + and vol - by the area of this surface (surf).

The reproducibility of these five parameters was determined from the scatter of the values in the 6 sets of contiguous MR images obtained with each sequence. The validity was assessed by relating the mean values of the 6 sets to the values determined from the anatomical sections.

\section{Results}

Qualitative evaluation of the anatomical sections and the MR images

Macroscopic assessment of the articular surface revealed a localized cartilage lesion, located at the secondary ridge (between the paramedian segment and the "odd facet") half way between the upper and the lower poles of the patella. The surface of the cartilage was fibrillated in this area, but no ebur- 

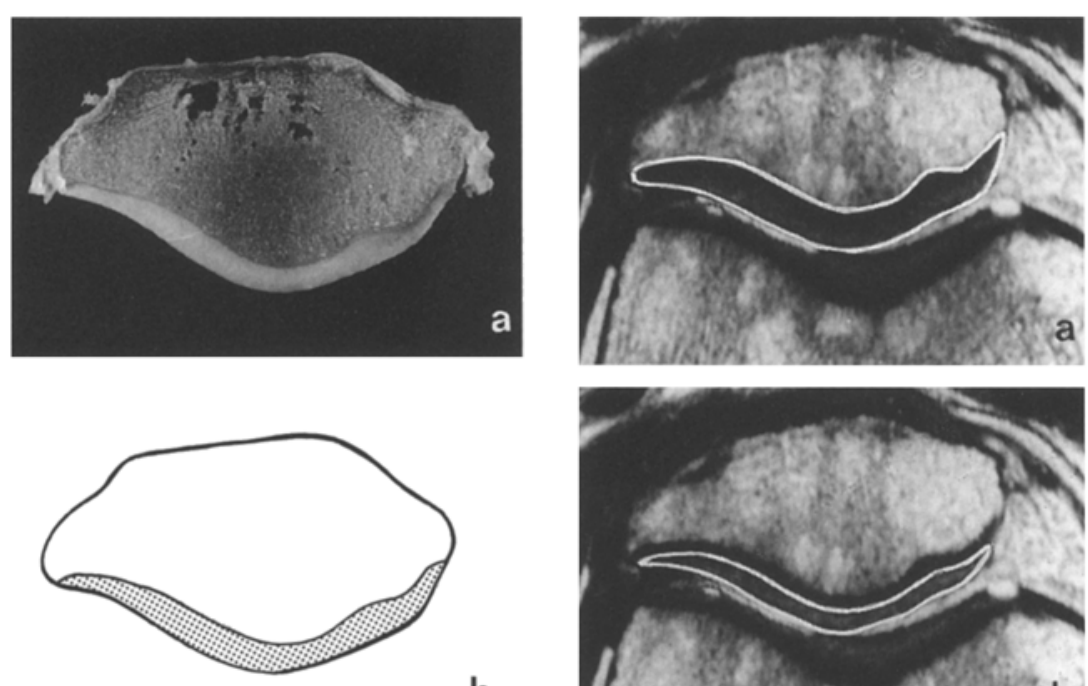

b
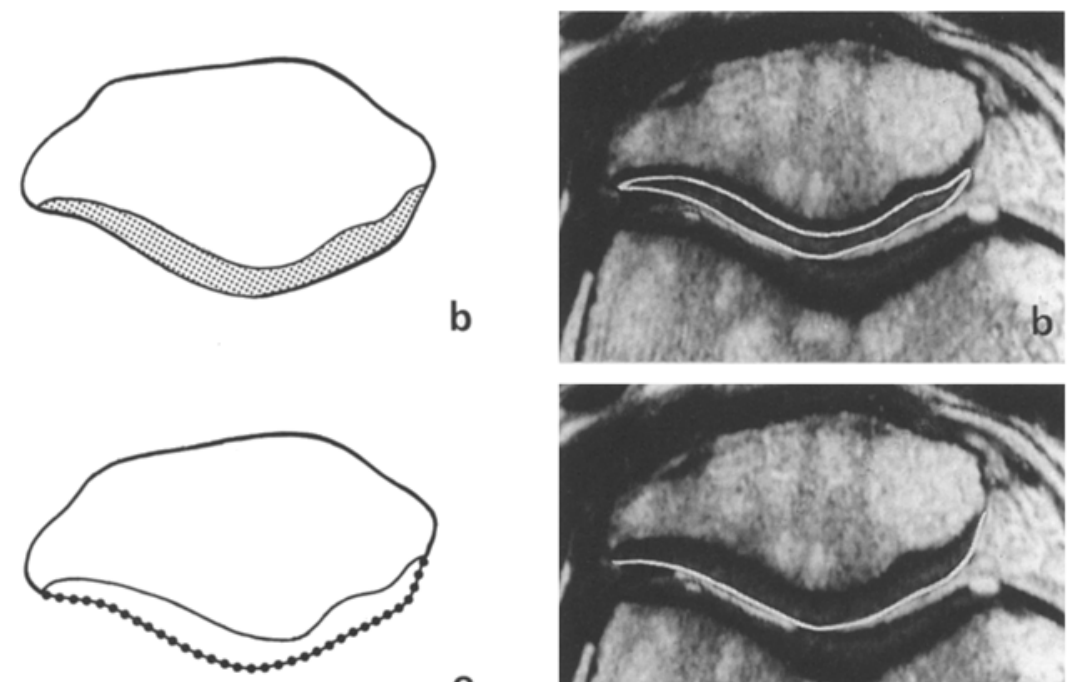

1
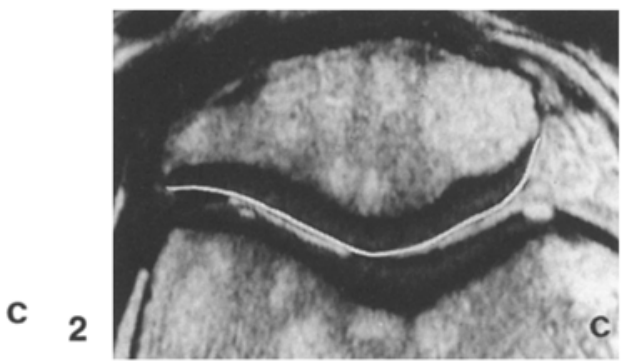

Fig. la-c (left column)

Image analysis of the anatomical sections (section interval = $2 \mathrm{~mm}$ ); a photograph of a section; b determination of the extent $\left(\mathrm{mm}^{2}\right)$ of the articular cartilage in the section; $\mathbf{c}$ determination of the length $(\mathrm{mm})$ of the articular surface in the section (dotted line in the picture)

Analyse de l'image des coupes anatomiques (espace intercoupe : $2 \mathrm{~mm}$ ) ; a photographie de la coupe ; b détermination de l'extension de la surface $\left(\mathrm{mm}^{2}\right)$ du cartilage articulaire de la coupe ; c détermination de la longueur $(\mathrm{mm})$ de la surface articulaire de la coupe (en pointillés sur les schéma)

\section{Fig. 2a-c (right column)}

Image analysis of the MR images (slice / partition thickness $=2 \mathrm{~mm}$ ), a determination of the extent $\left(\mathrm{mm}^{2}\right)$ of the articular cartilage in the image with inclusion of the low-signal layer in the transitional zone between cartilage and subchondral bone; $\mathbf{b}$ determination of the extent $\left(\mathrm{mm}^{2}\right)$ of the articular cartilage in the image without inclusion of the low-signal layer in the transitional zone between cartilage and subchondral bone; $c$ determination of the length $(\mathrm{mm})$ of the articu" lar surface

Analyse de l'image IRM (épaisseur de coupe $2 \mathrm{~mm}$ ); a détermination de la surface $\left(\mathrm{mm}^{2}\right) \mathrm{du}^{\circ}$ cartilage articulaite de l'image avec inclusion de la couche en hyposignal de la zone transition" nelle entre le cartilage et l'os sous-chondral; $\mathbf{b}$ détermination de la surface $\left(\mathrm{mm}^{2}\right)$ du cartilage articulaire de l'image sans inclusion de la couche en hyposignal de la zone transitionnelle entre le cartilage et l'os sous-chondral ; $\mathbf{c}$ détermination de la longueur (mm) de la surface articulaire

nation of the subchondral bone was evident, thus corresponding to "open chondromalacia patellae" as described by Ficat and Hungerford [7]. The lesion measured about $8 \mathrm{~mm}$ in diameter and was classified as grade 3 of Outerbridge's classification [28]. In Figure 3, a sagittal scout view is shown, indicating the level of the anatomical sections of Figure 4 (intact cartilage) and Figure 5 (medial cartilage lesion).
Fig. 4 (next page)

Transverse anatomical section through the patella; intact cartilage

Coupe anatomique transversale de la patella; cartilage intact

Fig. 5 (next page)

Transverse anatomical section through the patella; grade 3 cartilage lesion at the secondary (medial) ridge

Coupe anatomique transversale de la patella; lésions cartilagineuses de grade III de la crête secondaire médiale

Fig. 6a-f (next page, middle column)

Transverse MR images at the level of the anatomical sections shown in Fig. 4 obtained with various pulse sequences: a T1-SE, b MPRAGE, c FISP, d MTC-FISP, e DESS, f FLASH

Images IRM transversales au même niveau que les coupes anatomiques montrées à la figure 4, obtenues avec des séquences variées : a SE-T1; b MPRAGE ; c FISP ; d MTCFISP ; e DESS ; f FLASH

Fig. 7a -f (next page, right column) Transverse MR images at the level of the anatomical sections shown in Fig. 5 obtained with various pulse sequences: a T1-SE, b MPRAGE, c FISP, d MTC-FISP, e DESS, f FLASH

Images IRM transversales au niveau des coupes anatomiques montrées à la figure 5 , obtenues avec des séquences variées : a SETI ; b MPRAGE ; c FISP ; d MTC-FISP ; e DESS ; f FLASH

MR images at corresponding locations are presented in Fig. 6a-f and Fig. 7a-f. In these the articular cartilage appeared to be more or less homogeneous, although signal intensity and contrast varied widely from sequence to sequence. The extent of the low-signal layer at the transition from cartilage to subchondral bone was much wider in the T1-weighted spin-echo (Figs. $6 \mathrm{a}, 7 \mathrm{a})$ and the MPRAGE sequences (Figs. 6b, 7b) than in the other gradient-echo sequences. In the MPRAGE and FISP sequences (Figs. 6b, $c$ and $7 \mathrm{~b}, \mathrm{c}$ ), the femoral and patellar cartilage layers were difficult to distinguish from each other owing to poor contrast with the synovial fluid. The DESS 


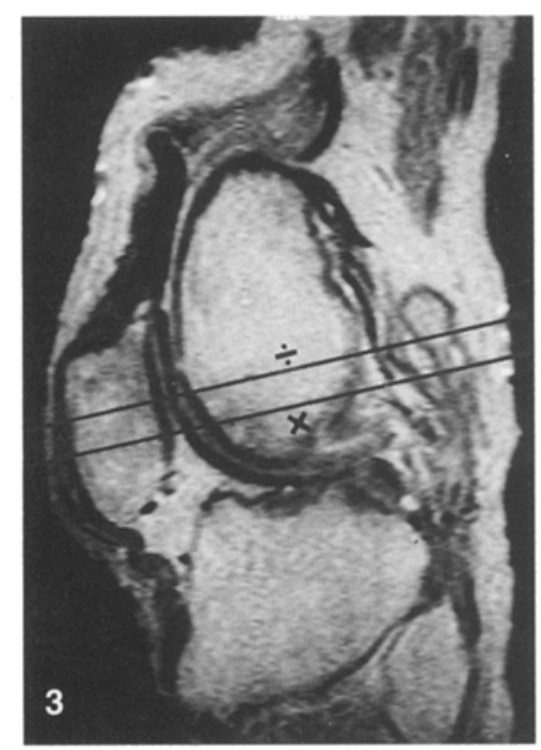

Fig. 3

Sagittal scout view, showing the level of the anatomical sections in Fig. $4(X)$ and Fig. 5 $(\div)$ and the MR images in Fig. 6a-f $(X)$ and Fig. $7 \mathrm{a}-\mathrm{f}(\div)$

Coupe de repérage sagittale démontrant le niveau des coupes anatomiques des figures 4 $(X)$ et $5(\div)$ et les images IRM des figures $6 a-f(X)$ et $7 a-f(\div)$
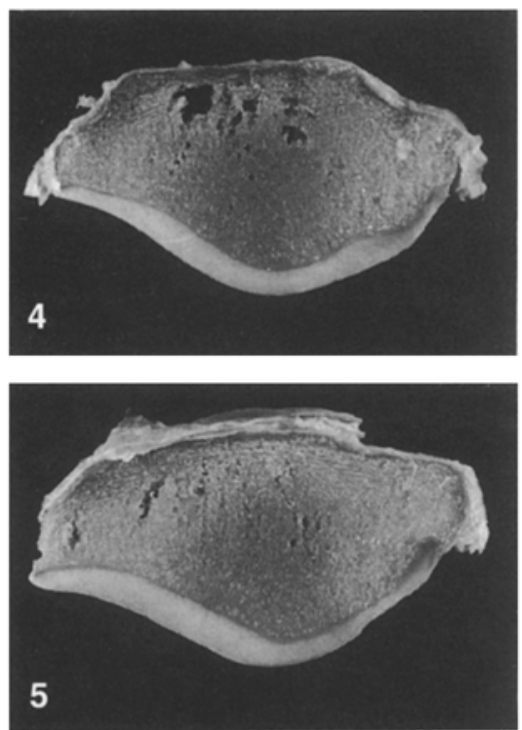
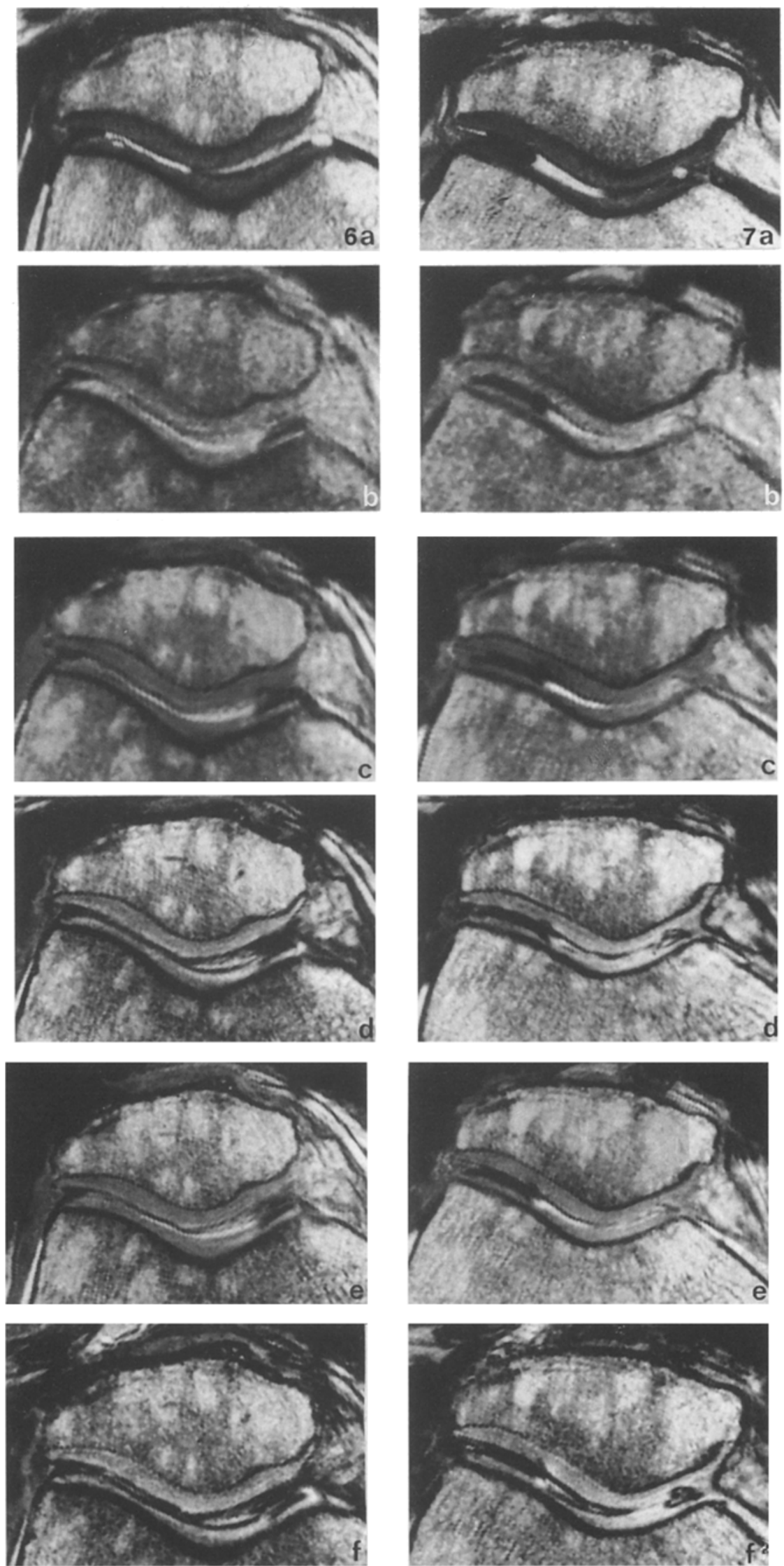


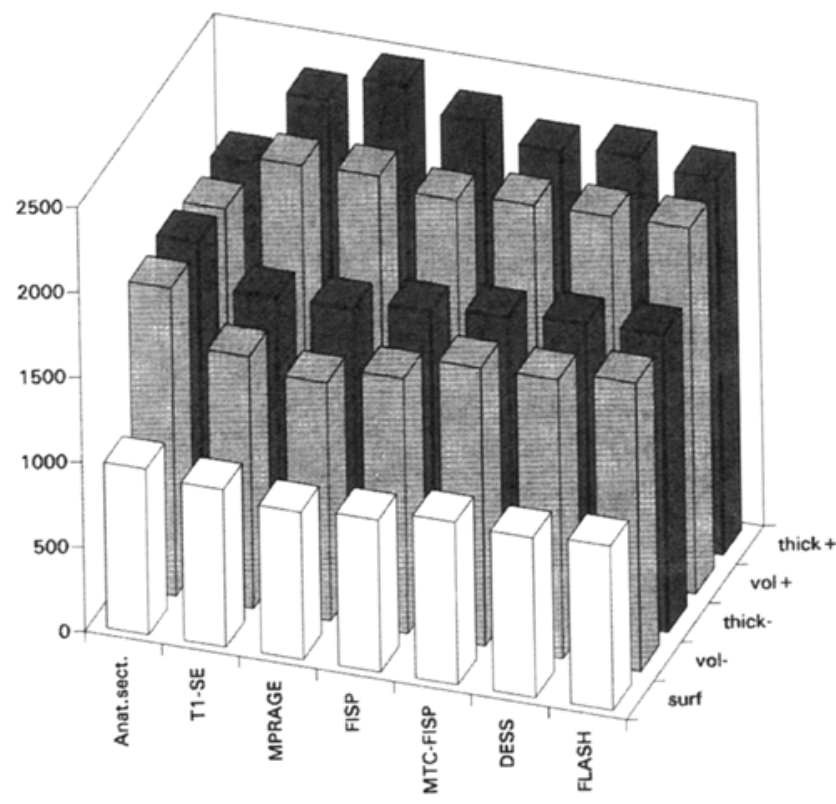
calculated from vol-and surf, vol $+=$ total volume of the articular cartilage determined from the proximal side of the anatomical sections $\left(\mathrm{mm}^{3}\right)$, and determined from the MR images with inclusion of the low-signal layer in the transitional zone between cartilage and subchondral bone $\left(\mathrm{mm}^{3}\right)$, thick $+=$ mean articular cartilage thickness $(\mu \mathrm{m})$ calculated from vol + and surf

Surface articulaire, volume cartilagineux total et épaisseur cartilagineuse moyenne déterminés à partir des coupes anatomiques et des séquences variées; surf = taille de la surface articulaire en $\mathrm{mm}^{2}$, vol- = volume total du cartilage articulaire, déterminé à partir du côté distal des coupes anatomiques $\left(\mathrm{mm}^{3}\right)$ et déterminé à partir des images IRM sans inclusion de la couche en hyposignal de la zone transitionnelle entre le cartilage et l'os sous-chondral $\left(\mathrm{mm}^{2}\right)$, thick- = épaisseur moyenne du cartilage articulaire $(\mu \mathrm{m})$ calculée à partir de vol- et surf, vol $+=$ volume total du cartilage articulaire déterminé à partir de la face proximale des coupes anatomiques $\left(\mathrm{mm}^{3}\right)$ et déterminée à partir des images IRM avec inclusion de la couche en hyposignal de la zone transitionnelle entre le cartilage et l'os sous-chondral $\left(\mathrm{mm}^{3}\right)$, thick $+=$ épaisseur moyenne du cartilage articulaire $(\mu \mathrm{m})$ calculé à partir de vol + et surf

Table 2. Size of the articular surface, total cartilage volume and mean cartilage thickness as determined from the MR images with the various pulse sequences

Surface articulaire, volume cartilagineux total et épaisseur moyenne du cartilage déterminés à partir des images IRM avec des séquences variées

\begin{tabular}{lcccccc}
\hline & T1-SE & MPRAGE & FISP & MTC-FISP & DESS & FLASH \\
\hline surf & 931 & 873 & 900 & 962 & 946 & 970 \\
vol + & 2153 & 2163 & 2098 & 2142 & 2150 & 2156 \\
vol - & 1485 & 1405 & 1506 & 1643 & 1648 & 1705 \\
thick + & 2.31 & 2.47 & 2.33 & 2.23 & 2.27 & 2.22 \\
thick - & 1.60 & 1.61 & 1.67 & 1.71 & 1.74 & 1.76 \\
\hline
\end{tabular}

Size of the joint surface $=\operatorname{surf}\left(\right.$ in $\left.\mathrm{mm}^{2}\right)$; volume of the cartilage with inclusion of the lowsignal layer in the transitional zone between cartilage and bone $=$ vol+ $\left(\right.$ in $\left.\mathrm{mm}^{3}\right)$; volume of the cartilage without inclusion of the low-signal layer $=$ vol- (in $\mathrm{mm}^{3}$ ), mean cartilage thickness with inclusion of the low-signal layer = thick + (in $\mathrm{mm}$ ); mean cartilage thickness without inclusion of the low-signal layer $=$ thick- $($ in $\mathrm{mm}$ )

La taille de la surface articulaire $=\operatorname{surf}\left(\mathrm{en}^{\mathrm{mm}} \mathrm{m}^{2}\right)$; le volume du cartilage avec inclusion de la couche en hyposignal de la zone transitionnelle entre le cartilage et l'os $=$ vol $+\mathrm{en}^{\mathrm{mm}^{3}}$; le volume du cartilage sans inclusion de la couche en hyposignal $=$ vol- $\left(\mathrm{en} \mathrm{mm}^{3}\right)$, l'épaisseur moyenne du cartilage avec inclusion de la couche en hyposignal = thick $+(\mathrm{en} \mathrm{mm}) ;$ l'épaisseur moyenne du cartilage sans inclusion de la zone en hyposignal $=$ thick $-(\mathrm{en} \mathrm{mm})$ sequence (Figs. 6e, 7e) allowed a much better differentiation of cartilage and fluid. The contrast of cartilage and periarticular soft tissues (fat, synovial folds etc.) was, however, inferior. The FISP sequence with the MTC pre-pulse (Figs. 6d, $7 d$ ) and the FLASH sequence (Figs. 6f, 7f), on the other hand, permitted adequate distinction of the cartilage from all other periarticular tissues. The cartilage lesion on the medial facet (Fig. 5) could be identified with both the MTC-FISP (Fig. 7e) and the FLASH sequences (Fig. 7f), the latter providing the better delineation.

\section{Quantitative determination of cartilage morphology in anatomical sections and MR images}

The measurements of the proximal and distal sides of the anatomical sections yielded little difference. The size of the articular surface was determined as $978 \mathrm{~mm}^{2}$ (977.9 and $978.5 \mathrm{~mm}^{2}$ ), the cartilage volume as $1816 \mathrm{~mm}^{3}$ (1820 and $1812 \mathrm{~mm}^{3}$ ), and the mean cartilage thickness as $1,86 \mathrm{~mm}$ (1.861 and $1.852 \mathrm{~mm})$. Assessment of the reproducibility of the measurements with the image analysing system produced a $\mathrm{Cv}$ of $3.1 \%(\mathrm{Cv}=$ coefficient of variation $=$ standard deviation as a percentage of the mean) for determining the extension of the cartilage in the sections (Fig. 1b), and $0.7 \%$ for determining the length of the articular surface (Fig. 1c).

The results obtained from the MR images are shown in Table 2, the data representing mean values of the six sets of contiguous images. The variation of these values from those determined from the anatomical sections is listed in Table 3 (see also Fig. 8).

Measurement of the size of the joint surface with the FLASH and the MTC-FISP sequences resulted in values which agreed rather well 
Table 3. Validity of the values determined from the MR images with the various pulse sequences

Validité des valeurs déterminées à partir des images IRM avec les différentes séquences

\begin{tabular}{lcccccc}
\hline & T1-SE & MPRAGE & FISP & MTC-FISP & DESS & FLASH \\
\hline surf & $-4,8 \%$ & $-10,7 \%$ & $-8,0 \%$ & $-1,6 \%$ & $-3,2 \%$ & $-0,8 \%$ \\
vol + & $+18,6 \%$ & $+19,1 \%$ & $+15,5 \%$ & $+18,0 \%$ & $+18,3 \%$ & $+18,7 \%$ \\
vol - & $-18,2 \%$ & $-22,6 \%$ & $-17,1 \%$ & $-9,5 \%$ & $-9,3 \%$ & $-6,1 \%$ \\
thick + & $+24,5 \%$ & $+33,2 \%$ & $+25,6 \%$ & $+20,2 \%$ & $+22,4 \%$ & $+19,7 \%$ \\
thick - & $-13,8 \%$ & $-13,2 \%$ & $-10,0 \%$ & $-7,8 \%$ & $-6,2 \%$ & $-5,1 \%$ \\
\hline
\end{tabular}

Difference between the mean values of 6 sets of MR images and the values determined from the anatomical sections (in \%)

Différence entre les valeurs moyennes de 6 séries d'images IRM et les valeurs déterminées à partir des coupes anatomiques (en \%)

Table 4. Reproducibility of the values obtained from the MR images with the various pulse sequences

Reproductibilité des valeurs obtenues à partir des images IRM avec les différentes séquences

\begin{tabular}{lcccccc}
\hline & T1-SE & MPRAGE & FISP & MTC-FISP & DESS & FLASH \\
\hline surf & $+/-2,0 \%$ & $+/-2,0 \%$ & $+/-2,3 \%$ & $+/-1,6 \%$ & $+/-0,8 \%$ & $+/-0,8 \%$ \\
vol $+\quad+/-3,2 \%$ & $+/-2,2 \%$ & $+/-3,5 \%$ & $+/-1,9 \%$ & $+/-2,2 \%$ & $+/-2,0 \%$ \\
vol - & $+/-7,0 \%$ & $+/-5,4 \%$ & $+/-4,3 \%$ & $+/-3,1 \%$ & $+/-5,9 \%$ & $+/-2,9 \%$ \\
thick $+\quad+/-2,2 \%$ & $+/-2,4 \%$ & $+/-2,0 \%$ & $+/-1,8 \%$ & $+/-2,8 \%$ & $+/-2,0 \%$ \\
thick - $\quad+/-6,2 \%$ & $+/-5,7 \%$ & $+/-2,5 \%$ & $+/-3,8 \%$ & $+/-6,1 \%$ & $+/-2,6 \%$ \\
\hline
\end{tabular}

$C v$ (= coefficients of variation $=$ standard deviation as a percentage of the mean $)$ as determined from 6 sets of MR images

$C v(=$ coefficient de variation $=$ déviation standard en $\%$ de la moyenne $)$, déterminé à partir de 6 séries d'images IRM

with those obtained from the anatomical sections $(-0.8 \%$ and $-1.6 \%)$. The other sequences underestimated the surface by up to $10.7 \%$ (Table 3 , Fig. 8). With the low-signal layer, an overestimation of the total volume of articular cartilage of about $18 \%$ was found in all sequences. Without this layer, the volumes in the MR images were less than those derived from the anatomical sections, the largest deviations being found with MPRAGE and T1-SE, and the smallest with the FLASH sequence (Table 3, Fig. 8).

When the low-signal layer was included in the calculation of articular cartilage thickness, the values were 19.7 to $33.2 \%$ higher than those determined from the anatomical sections. When it was not included, the smallest deviation was obtained with the FLASH sequence $(-5.1 \%)$, whereas the other sequences underestimated it by up to $-13.8 \%$ (Table 3, Fig. 8).

The reproducibility of the parameters is specified in Table 4. The $\mathrm{Cv}$ for repetitve determination of the size of the articular surface (from 6 sets of images) was between $0.8 \%$ (FLASH and DESS) and $2.3 \%$ (FISP). Lower values (i.e. more reproducible results) were found with sequences which provide higher visual contrast between cartilage and the adjacent tissues. The lowest reproducibility of carti- lage volume and thickness was obtained with the T1-SE sequence, the highest with the FLASH sequence.

\section{Discussion \\ Methodology of validation}

High precision of the measurements can be guaranteed, since the determination of the relevant areas and distances was reliably reproduced on repetitive evaluation by image analysis. The anatomical cartilage volume, the size or the articular surface and the cartilage thickness were determined once from the proximal and once from the distal sides of the anatomical sections, showing that the parameters were only slightly dependent on the position of the sections through the joint surface in this specimen. Therefore, it was not crucial to define identical levels for the MR images and the anatomical sections.

In contrast to previous studies which have tried to quantitatively evaluate cartilage thickness in MR images $[6,15,16,45]$, a deviation of the measurements due simply to a non-correspondence of measuring points could be excluded by choosing this volumetric approach. The relatively flat patella allowed the anatomical sections to be cut perpendicular to the whole articular surface. By making use of the multiplanar capabilities of MRI and employing consecutive scout views, an identical angulation of the images with that of the anatomical sections was achieved.

\section{Morphology of the articular cartilage}

In contrast to some other investigatiors $[18,25,30,33]$, we obtained a relatively homogeneous signal intensity from articular cartilage; no 
differentiation of several layers could be found. However, the slice thickness and the orientation of image planes may be responsible for this finding. The so-called "magic angle" $[18,33]$, -result of a preferential direction of the collagen fibres in the patellar cartilage- may also play an important role in this. As mentioned in other studies [1, 19], the thickness of the transitional low-signal zone between the cartilage and the subchondral bone depends on the sequence employed. In our investigation, the inclusion of this region resulted in an overestimation of the cartilage volume by a fairly constant factor. This is in agreement with the observation of other authors that the low-signal zone cannot be entirely attributed to the articular cartilage $[1,30,33]$. This "zone" may, at least in part, be an artifact of MRI $[1,9,19]$ and cannot be taken to fully correspond with an anatomical reality.

However, when the low-signal layer was not included in the measurement, the cartilage volumes determined from the various pulse sequences were all less than those from the anatomical sections.

With the T1-weighted spin-echo sequence (T1-SE), the volume was underestimated to almost the same extent that it was overestimated when the layer was included. With this sequence the «truth» literally lies halfway between the two approaches. Although T1-SE is a commonly used sequence in clinical diagnostics $[5,6,10-12,14-16,41$, 47], our results support the views of König et al. [19] and Adam et al. [1] that spin-echo sequences do not permit a precise morphometric assessment of articular cartilage thickness. The size of the articular surface was underestimated by about $5 \%$, suggesting that cartilage is not entirely recognized as such. Parts of the articular surface, supposedly where the cartilage is thin, will not be made visible at all by the spin-echo sequence.

MPRAGE, a T1-weighted gradient-echo sequence [3] that can be optimized for the delineation of articular cartilage [29], does not seem to improve the demonstration of cartilage thickness. The articular surface and the cartilage volume were significantly underestimated. The FISP (or GRASS) sequence [2, $11-13,34,38,46]$ proved to be equally inadequate for this purpose in this study. The artifacts in the transitional zone between cartilage and bone were less obvious than with the spin-echo sequence and MPRAGE, but it was difficult to distinguish cartilage from synovial fluid. This impaired the valid determination of the cartilage thickness. However, more accurate values were obtained when magnetic transfer contrast (MTC) was used with the FISP sequence. The MTC prepulse enhances the contrast between specific tissue pairs [42], such as synovial fluid and articular cartilage $[43,44]$. The inherent magnetization transfer effect was first quantified by Forsen and Hoffmann [8] and has recently be shown to depend on the presence of hydroxyprolingroups in the collagen fibres of the cartilage [17]. Our results indicate that MTC brings about a higher validity and reproducibility of the morphometric measurements, since the articular cartilage can be more clearly distinguished from the neighbouring tissues. The volume of the cartilage is still underestimated, but to a much smaller degree than with the spin-echo sequence.

DESS (dual echo at steady state), which combines a FISP-like image with the strong $\mathrm{T} 2$-contrast of a second echo [4], has been advocated to bring about an even sharper contrast between articular cartilage and synovial fluid than MTC [29]. Our results suggest that DESS is as adequate for the delineation of the cartilage volume as the MTC-FISP sequence. The determination of the size of the articular surface and the reproducibility, on the other hand, were less satisfactory, possibly because of the lower contrast between cartilage, fat and synovial folds.

However, in this study the most valid and reproducible results were achieved with the FLASH sequence. FLASH is available on many MR scanners and has been widely used in clinical practice $[2,19,20,27$, 32]. The FLASH sequence also allowed the clearest delineation of the grade 3 cartilage damage near the medial secondary ridge, which is in agreement with observations of Reiser at al. [32] and Nakanishi et al. [27]. However, no conclusions should be drawn from this single finding as to the sensitivity of the described sequences for depicting articular cartilage lesions in their very early state. Signal abnormalities (hyperintensity or hypointensity) may possibly be the first feature in cartilage disorders, especially in chondromalacia grades 1 and 2 . This phenomenon has, however, not been the subject of the present investigation, which has been addressed to the question, whether MR allows accurate determination of the articular cartilage volume and thickness.

Fat suppression, which may be combined with some of the sequences tested [30, 37], holds promise for even higher contrast-tonoise ratios of articular cartilage and the periarticular tissues. Attempts to employ this technique in the current study failed, probably due to the fact that the specimen had been embalmed in a formalin-alcohol fixative. It will have to be determined in future studies, whether this technique indeed allows an easier and more precise assessment of cartilage thickness.

Even with the FLASH sequence the measurements of these parame- 
ters in MR images did not fully agree with the anatomical values. It should, however, not be forgotten that, in the anatomical sections, the dividing line between the white cartilage and the darker subchondral region represents the transition from the calcified cartilage to the subchondral bone. Therefore the calcified zone of the cartilage is included in the values of the anatomical measurement. According to MüllerGerbl et al. [26], the width of this calcified cartilage amounts to 3.2 to $8.8 \%$ of the total cartilage thickness. The underestimation of the cartilage volume in MRI by about $6 \%$ could therefore well be due to the fact that the calcified zone of the cartilage is not made visible as such on the images, but constitutes part of the low-signal layer in the transitional zone of bone and cartilage [33]. Nevertheless, the calcified zone has been shown to exhibit a positive correlation with the total thickness of the articular cartilage [26], and the "relative distribution" of articular cartilage thickness might therefore be accurately demonstrated by MRI. The possibility of precise assessment of articular cartilage thickness offers attractive features in comparison with arthroscopy, which is more invasive and restricted to the evaluation of the articular surface.

In conclusion it may be stated:

- MRI provides useful information on the morphology of the articular cartilage, and its validity may be further improved by more sophisticated pulse sequences,

- cartilage volume and cartilage thickness were more validly determined when the low-signal layer in the transitional zone between cartilage and bone was not included in the measurement,

- with three-dimensional gradient-echo sequences better results were achieved than with spin-echo sequences,
- FLASH (fast low angle shot) provided the most valid and reproducible values compared with the other sequences tested in this study, - the remaining disparity between MR images and anatomical sections may be due to the fact that MRI does not make visible the calcified zone of the cartilage.

Acknowledgements. We would like to thank Ms Claudia Dinter for preparing the photographs, $\mathrm{Mr}$ Ulrich Maier and Mr Horst RuB for their help in providing the figures and Dr. Francis Steel for discussing the text.

\section{References}

1. Adam $G$, Bohndorf $K$, Prescher A, Krasny R, Günther RW (1988) Der hyaline Gelenkknorpel in der MR Tomographie des Kniegelenks bei 1,5 T. RÖFO 148 : 648-651

2. Adam G, Bohndorf K, Prescher A, Drobnitzky M, Günther W (1989) Kernspintomographie der Knorpelstrukturen des Kniegelenks mit 3D-Volumen-Imaging in Verbindung mit einem schnellen Bildrechner. RÖFO $150: 44-48$

3. Brant-Zawadzki M, Gillan GD, Nitz WR (1992) MP RAGE: a three-dimensional, $T 1$-weighted, gradient-echo sequenceinitial experience in the brain. Radiology $182: 769-775$

4. Bruder $H$, Fischer $H$, Graumann R, Deimling M (1988) A new steady-state imaging sequence for simultaneous acquisition of two MR images with clearly different contrasts. Magn Res Med 7: 35-42

5. Mc Cauley TR, Kier R, Lynch KJ, Jokl P (1992) Chondromalacia patellae. Diagnosis with MR imaging. AJR 158 : 101105

6. Chandnani VP, Ho C, Chu P, Trudell D, Resnick D (1991) Knee hyaline cartilage evaluated with MR imaging: a cadaveric study involving multiple imaging sequences and intraarticular injection of gadolinium and saline solution. Radiology $178: 557-561$

7. Ficat P, Hungerford DS (1977) Disorders of the patellofemoral joint. Masson, Paris

8. Forsen S, Hoffmam RA (1963) Study of moderately rapid chemical exchange reactions by means of nuclear double resonance. J Chem Phys 39 : 2892-2901
9. Freeman DM, Bergmann AG, Hurd RE, Glover G (1993) Accurate measurement of hyaline cartilage and cortical bone thickness using short TE MR microscopy. Society of Magnetic Resonance in Medicine, 12 th annual meeting, New York, Book of abstracts, p 880

10. Gylys-Morin VM, Hajek PC, Sartoris DJ, Resnick D (1987) Articular cartilage defects: Detectibility in cadaver knees with MR. AJR 148 : 1153-1157

11. Handelberg F, Shahabpour M, Casteleyn PP (1990) Chondral lesions of the patella evaluated with computed tomography, magnetic resonance inaging, and arthroscopy. Arthroscopy $6: 24-29$

12. Hayes CW, Sawyer RW, Conway WF (1990) Patellar cartilage lesions: in vitro detection and staging with MR imaging and pathologic correlation. Radiology $176: 479-483$

13. Heron CW, Calvert PT (1992) Threedimensional gradient-echo MR imaging of the knee: comparison with arthroscopy in 100 patients. Radiology $183: 839$ 844

14. Hodler J, Berthiaume MJ, Schweitzer ME, Resnick D (1992) Knee joint hyaline cartilage defects: a comparative study of MR and anatomic sections. J Comput Assist Tomogr $164: 597-603$

15. Hodler J, Trudell D, Pathria $M N$, Resnick D (1992) Width of the articular cartilage of the hip: quantification by asing fat-suppression spin-echo MR imaging in cadavers. AJR 159:351-359

16. Johnsson $\mathrm{K}$, Buckwalter K, Helvie M, Niklason L, Martel W (1992) Precision of hyaline cartilage thickness measurements. Acta Radiol $33: 234-239$

17. Kim DK, Ceckler TL, Hascall VC, Calabro A, Balaban S (1993) Analysis of water-macromolecule proton magnetization transfer in articular cartilage. Magn Res Med 29: 211-215

18. Kim JK, Rubenstein JD, Johnson GA, Henkelmann RM (1993) High Resolution MRI of bovine articular cartilage. Society of Magnetic Resonance in Medicine, 12th annual meeting, New York, Book of abstracts, $p 410$

19. König H, Sauter R, Deimling $M$, Vogt $M$ (1987) Cartilage disorders: comparison of spin-echo, Chess, and Flash sequence MR images. Radiology $164: 753-758$

20. König H, Aicher K, Klose U, Saal J (1990) Quantitative evaluation of hyaline cartilage disorders using Flash sequence. Clinical applications. Acta Radiol 31 : $377-381$

21. Kramer J, Stiglbauer R, Engel A Prayer L, Imhoff H (1992) MR contrast arthrography (MRA) in osteochondrosis disse- 
cans. J Comput Assist Tomogr $16: 254$ 260

22. Kusaka Y, Gründer W, Rumpel H, Dannhauer KH, Gersonde K (1992) MR microimaging of articular cartilage and contrast enhancement by manganese ions. Magn Res Med 24 : 137-148

23. Lehner KB, Rechl HP, Gmeinwieser IK, Heuck AF, Lukas HP, Kohl HP (1989) Structure, function, and degeneration of bovine hyaline cartilage: assessment with MR imaging in vitro. Radiology $170: 495-499$

24. Lenz GW, Goldmann AR, Deimling M, Boettcher U (1993) Improvement of synovial fluid contrast in the knee with MTC and DESS at $0,2 \mathrm{~T}$. Society of Magnetic Resonance in Medicine, 12 th annual meeting, New York, Book of abstracts, $\mathrm{p} 181$

25. Modl IM, Sether LA, Haughton VM, Kneeland JB (1991) Articular cartilage: correlation of histologic zones with signal intensity at MR imaging. Radiology $181: 853-855$

26. Miiller-Gerb1 M, Putz R, Schulte E (1987) The thickness of the calcified layer of articular cartilage: a function of the load supported? J Anat $154: 103-111$

27. Nakanishi $K$, Inoue $M$, Ikezoe KHJ, Murakami $T$, Nakamura $H$, Kozuka $T$ (1992) Subluxation of the patella: evaIuation of patellar articular cartilage with MR imaging. Br J Radiol 65 : 662-667

28. Outerbridge RE (1964) Further studies on the etiology of chondromalacia patellae. J Bone Joint Surg[Br] 46-B : 149190

29. Piraino D, Recht M, Hardy P, Schils J, Richmond B, Belhobek G (1993) The optimization of 3 D MPRAGE for imaging knee cartilage. Society of Magnetic Resonance in Medicine, 12th annual meeting, New York, Book of abstracts, $p$ 865

30. Recht MP, Kramer J, Marcelis S, Pathria
MN, Trudell D, Haghighi P, Sartoris DJ, Resnick D (1993) Abnormalities of articular cartilage in the knee: analysis of available MR techniques. Radiology $187: 473-478$

31. Reicher MA, Rauschning W, Gold RH, Bassett LW, Lufkin RB, Glen W (1985) High-resolution magnetic resonance imaging of the knee joint: normal anatomy. AJR $145: 895-902$

32. Reiser MF, Bongarz G, Erlemann R, Strobel M, Pauly T, Gaebert K, Stoeber U, Peters PE (1988) Magnetic resonance in cartilaginous lesions of the knee joint with three-dimensional gradient-echo imaging. Skeletal Radiol $17: 465-471$

33. Rubenstein JD, Kim JK, Morava-Protzner I, Stanchey PL, Henkelmann RM (1993) Effects of collagen orientation on MR imaging characteristics of bovine articular cartilage. Radiology $188: 219$ 226

34. Speer KP, Spritzer CE, Goldner JL, Garrett WE (1991) Magnetic resonance imaging of traumatic articular cartilage injuries. Am J Sports Med 19:396-402

35. Steinbrich W, Beyer D, Friedmann G, Ermers JW, Bueß G, Schmidt KH (1985) MR des Kniegelenkes. RÖFO 143 : 166172

36. Thomas L (1992) Labor und Diagnose. Medizinische Verlagsgesellschaft, Marburg

37. Tottermann S, Weiss SL, Szumowski J, Katzberg RW, Hornak JP, Proskin HM, Eisen J (1989) MR Fat suppression technique in the evaluation of normal structures of the knee. J Comput Assist Tomogr $13: 473-479$

38. Tyrell RL, Gluckert K, Pathria M, Modic MT (1988) Fast three-dimensional MR imaging of the knee: comparison with arthiroscopy. Radiology $166: 865-872$

39. Vahlensieck M, Leutner C, Dombrowsky F, Vogel J, Träber F, de Boer R, Reiser M (1993) Magnetization transfer contrast
(MTC) of the human knee joint-detection of early cartilage degeneration. Society of Magnetic Resonance in Medicine, 12th annual meeting, New York, Book of abstracts, $p 881$

40. Vogel $\mathrm{H}$, Krüger L Hallata Z, Zander C (1986) Knorpel im Kernspintomogramm. Digit Bildiagn $6: 118-122$

41. Wojtys E, Mark W, Buckwalter K, Braunstein E, Martel W (1987) Magnetic resonance imaging of knee hyaline cartilage and intraarticular pathology. Am J Sports Med 15: 455-463

42. Wolff SD, Balaban RS (1989) Magnetization transfer contrast (MTC) and tissue water proton relaxation in vivo. Magn Res Med 10:135-144

43. Wolff SD, Chesnick S, Frank JA, Lim KO, Balban RS (1991) Magnetization transfer contrast: MR imaging of the knee. Radiology $179: 623-628$

44. Wolff SD, Eng J, Balaban RS (1991) Magnetization transfer contrast: method of improving contrass in gradient-recalled-echo images. Radiology 179 : 133137

45. Wrazidlo W, Schneider S, Richter GM, Kauffmann GW, Bläsius K, Gottschlich KW (1990) Darstellung des hyalinen Gelenkknorpels mit der MR-Tomographie mittels einer GradientenechoSequenz mit Fett Wasser-Phasenkohärenz. RÖFO $152: 56-59$

46. Yao L, Sinha S, Seeger LL (1992) MR imaging of joints: analytic optimization of GRE techniques at 1,5 T. AJR 158 : 339-345

47. Yulish BS, Montanez J, Goodfellow DB, Bryan PJ, Mulopulos GP, Modic MT (1987) Chondromalacia patellae: assessment with MR imaging. Radiology 164 : 763-766

Received January 31, 1994/Accepted in final form October 15, 1994 